\title{
ON WEIGHTED QUASI-ARITHMETIC MEANS WHICH ARE CONVEX
}

\section{JACEK Chudziak, Dorota GŁAZOWska, Justyna JARCZYK AND Witold JARCZYK}

\begin{abstract}
We study convexity in the class of weighted quasi-arithmetic means. It turns out that their convexity depends only on the generator, neither on weights, nor on the number of variables. Connections between the convexity of a mean and the convexity of its increasing generators are considered. We prove that convex means are generated by convex strictly increasing functions. A simple example shows that the converse is not true, so the problem arises when this is the case. Some answers are given under regularity assumptions imposed on the generator.
\end{abstract}

Mathematics subject classification (2010): 26E60, 26B25, 39B62.

Keywords and phrases: Weighted quasi-arithmetic mean, convexity.

\section{REFERENCES}

[1] F. Bernstein, G. Doetsch, Zur Theorie der konvexen Funktionen, Math. Ann. 76 (1915), 514-526.

[2] Z. DARócZY, Zs. PÁLES, Convexity with given infinite weight sequences, Stochastica 11 (1987), $5-12$.

[3] G. H. Hardy, J. E. Littlewood, G. Pólya, Inequalities, Cambridge University Press, Cambridge, 1934 (1st edition), 1952 (2nd edition).

[4] M. Kuczma, An introduction to the theory of functional equations and inequalities. Cauchy's equation and Jensen's inequality (2nd edition), edited and with preface by Attila Gilányi, Birkhaüser, Basel, 2009.

[5] N. KuHN, A note on t-convex functions, General Inequalities 4 (Oberwolfach, 1983), 269-276, Internat. Schriftenreihe Numer. Math. 71, Birkhaüser, Basel, 1984.

[6] L. LosonczI, Subadditive mittelverte, Arch. Math. (Basel) 22 (1971), 168-174.

[7] Gy. MAKSA, Zs. PÁLES, Remarks on the comparison of weighted quasi-arithmetic means, Colloq. Math. 120 (2010), 77-84.

[8] T. MAŁOLEPSZY, oral communication.

[9] Zs. PÁLES, General inequalities for quasideviation means, Aequationes Math. 36 (1988), 32-56.

[10] Zs. PÁLES, P. PASTECZKA, On the best Hardy constant for quasi-arithmetic means and homogeneous deviation means, Math. Inequal. Appl. 21 (2018), 585-599. 